\title{
Brucella and non-Brucella epididymo-orchitis: comparison of ultrasound findings
}

\author{
Ali Haydar Baykan', Hakan Sezgin Sayiner², Ibrahim Inan 3 \\ ${ }^{1}$ Adiyaman University, Faculty of Medicine, Department of Radiology, ${ }^{2}$ Adiyaman University, Faculty of Medicine, \\ Department of Infectious Diseases and Clinical Microbiology, ${ }^{3}$ Biruni University Hospital, Department of Radiology, \\ Istanbul, Turkey
}

\begin{abstract}
Aim: In brucellosis the male genitourinary system can be affected in a small number of patients. In this study we aimed to identify, discuss and compare the radiologic findings of 24 cases with Brucella epididymo-orchitis (BEO) and 285 cases with non-Brucella epididymis orchitis (NBEO). Material and methods: The study had a retrospective design. The area of involvement, side of involvement (left, right or bilateral), presence of abscess, hydrocele and testicular involvement pattern were analyzed and compared between the BEO and NBEO cases. Results: The median age of the included cases was 33 years, with a minimum of 0 and maximum of 89 . Epididymo-orchitis and isolated orchitis were more frequent in BEO cases while isolated epididymis involvement was more common in patients with non-BEO $(\mathrm{p}=0.0117)$. Bilateral involvement was present in $20.8 \%$ and $4.6 \%$ cases in the BEO and non-BEO groups, respectively $(\mathrm{p}=0.008)$. The frequency of abscess was significantly higher in BEO cases $(p=0.003)$. Conclusion: Although the radiological indications of BEO are similar to those of other types of epididymo-orchitis, abscess formation, bilateral involvement and testicular involvement contribute significantly to diagnosis.

Keywords: Brucella; epididymo-orchitis; ultrasonography; testis
\end{abstract}

\section{Introduction}

Brucellosis is a zoonotic disease, transmitted by unpasteurized milk and contaminated dairy products. Brucella melitensis is the most common cause of the disease $[1,2]$. In brucellosis, the male genitourinary system is affected in a small number of patients; it is known that Brucella epididymo-orchitis (BEO) constitutes $2 \%$ to $20 \%$ of all brucellosis cases [3-5]. The most common symptoms of BEO are scrotal pain, scrotal swelling and fever $[2,6]$.

Received 08.01.2019 Accepted 21.04.2019

Med Ultrason

2019, Vol. 21, No 3, 246-250

Corresponding author: Ibrahim Inan

Department of Radiology, Biruni University

Hospital, 34295 Istanbul, Turkey

Phone: +90(506) 7444430

Fax: +90(212) 4164646

E-mail: ibrahimi@biruni.edu.tr
Ultrasonography (US) is the most frequent imaging technique used for the confirmation of epididymo-orchitis and the exclusion of testicular torsion. In BEO the US findings are varied: abscess formation, increased vascularity or diffuse/focal hypoechogenicity [2,7].

There are only a few published studies related to the imaging findings of BEO and the majority are case reports [8-12]. The number of radiological studies which compare BEO and non-BEO (NBEO) cases is very limited; in fact, to the best of our knowledge, only one such study is available in the literature [13].

Therefore, in the present study we aim to identify, discuss and compare the US findings of patients with $\mathrm{BEO}$ and NBEO diagnosed in our clinic.

\section{Material and methods}

This study has a retrospective design and the approval of the local Ethics Committee was obtained. Patients who 
had received a diagnosis of brucellosis between January 2014 and January 2018 were retrospectively analyzed and a totally 263 cases were identified. We excluded female patients $(n=134)$, those with non-testicular and epidydimal involvement $(\mathrm{n}=98)$ and cases for which the US reports and archived images were not available $(n=7)$. As a result, 24 male BEO patients were included in the study. Clinically, patients with scrotal pain, scrotal swelling or redness and Brucella serum agglutination titer $\geq 1 / 160$ were interpreted as BEO. The comparison was made with 285 male patients diagnosed with NBEO in the same period. Six patients with BEO and four patients with NBEO were evaluated also by magnetic resonance imaging (MRI). The treatment protocol and follow-up of the BEO patients were undertaken by an infectious disease specialist.

There was no preliminary preparation before the US evaluation. All cases were evaluated in supine position with both legs wide open using Toshiba Aplio 500 (Toshiba, Tokyo, Japan) linear probe with a frequency of 7.5-10 MHz. Philips Achieva 1.5 Tesla (Achieva; Philips Medical Systems, Best, Netherlands) device was used for MRI. Serial transvers and sagittal sonograms were obtained for each hemiscrotum. The presence of hydrocele in scrotum, swelling, heterogeneity, hypoechoic areas, abscess in testes and/or epidydime were noted. The presence of hypoechoic and/or heterogenic areas in the entire testis was considered as diffuse involvement. Testis with one small and limited hypoechoic lesion was considered to have focal involvement. More than one focal lesion was interpreted as multifocal involvement. The tumor like lesions are considered as pseudomass. The evaluation was undertaken by two radiologists, with seven and twelve years of experience.

\section{Statistical analysis}

SPSS Statistics v. 21.0 (IBM Corporation, New York, USA) software was used for statistical analysis. The categorical data were expressed as number and percentages, and the numerical data without normal distribution were expressed as minimum, maximum, and median values. Pearson's chi-square and Fisher's exact tests were used for the comparison of categorical data, and the MannWhiney U test was used for the comparison of nonparametric data between the groups. The results were considered statistically significant if the "p" value was below 0.05 .

\section{Results}

The age of patients included in the study ranged from 0 to 89 years and the median age was calculated to be 33 years. Twenty-four cases $(7.8 \%)$ were diagnosed with BEO and $285(92.2 \%)$ with NBEO. The mean age of the patients was $35.21 \pm 17.55$ and $35.12 \pm 21.61$ years for the BEO and NBEO groups, respectively, with no statistically significant difference between the groups $(\mathrm{p}=0.806)$.

The radiological findings such as involvement of epididyme and/or testes, involvement side (unilateral or bilateral) and involvement type of testicular parenchyma were summarized on Table I. The radiological findings of some cases are shown in figures 1 to 4 .

Table I. The US findings in Brucella non-Brucella epididymis orchitis groups

\begin{tabular}{|c|c|c|c|}
\hline & BEO n (\%) & NBEO n (\%) & p value \\
\hline Number of patients & 24 & 285 & \\
\hline \multicolumn{4}{|l|}{ Age (range) } \\
\hline Involved structures & & & 0.0117 \\
\hline Epididymo-orchitis & $16(66.7)$ & $153(53.7)$ & \\
\hline Isolated testicular involvement & $6(25)$ & $32(11.2)$ & \\
\hline Isolated epidydimal involvement & $2(8.3)$ & $100(35.1)$ & \\
\hline Involvement side & & & 0.008 \\
\hline Unilateral & $19(79.2)$ & $272(95.4)$ & \\
\hline Bilateral & $5(20.8)$ & $13(4.6)$ & \\
\hline Presence of abscess & $4(16.7)$ & $5(1.8)$ & 0.003 \\
\hline Increase of intrascrotal fluid & $10(41.7)$ & $147(51.6)$ & 0.351 \\
\hline Presence of septa & $2(20)$ & $32(21.8)$ & 0.628 \\
\hline Involvement type of testicular parenchyma & & & 0.008 \\
\hline Diffuse & $15(71.4)$ & $163(88.1)$ & \\
\hline Multifocal & $3(14.3)$ & $11(5.9)$ & \\
\hline Focal & $2(9.5)$ & $11(5.9)$ & \\
\hline Pseudomass & $1(4.8)$ & $0(0)$ & \\
\hline Total & $24(7.8)$ & $285(92.2)$ & - \\
\hline
\end{tabular}

$\mathrm{N}$, number of pateints; BEO, Brucella epididymo-orchitis; NBEO, non-Brucella epididymis orchitis 


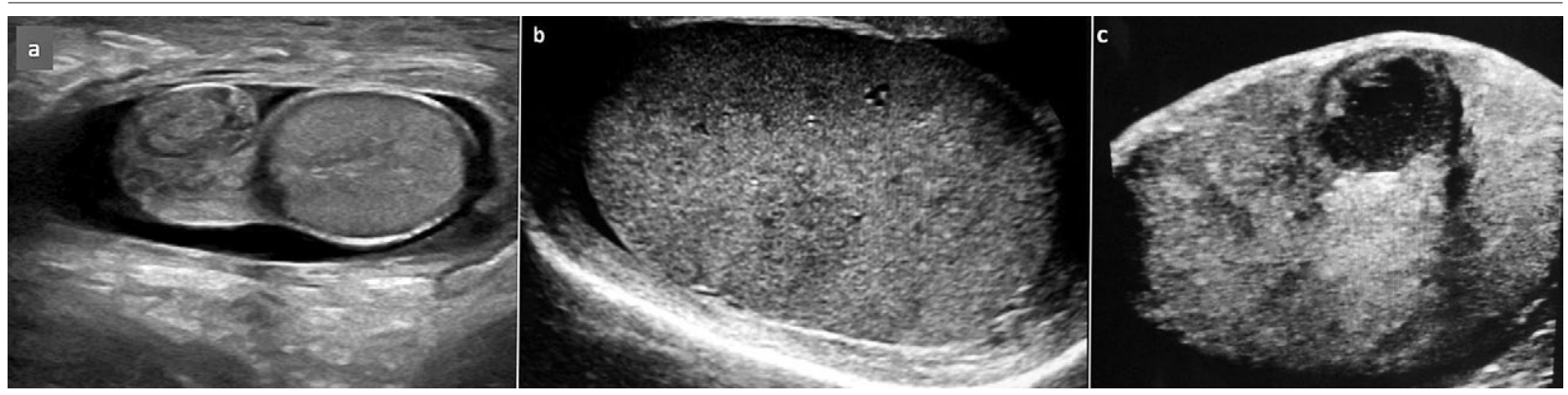

Fig 1. Ultrasonographic images of BEO cases: a) isolated epididymitis with enlarged, heterogeneous epididymis in a three-year-old patient; b) US image of a 24-year-old male demonstrates geographically, heterogeneous, hypoechoic areas related with orchitis; c) a thick-walled testicular abscess accompanied by a hypoechoic heterogenous appearance of the neighboring testicular parenchyma in a 38 -year-old case.
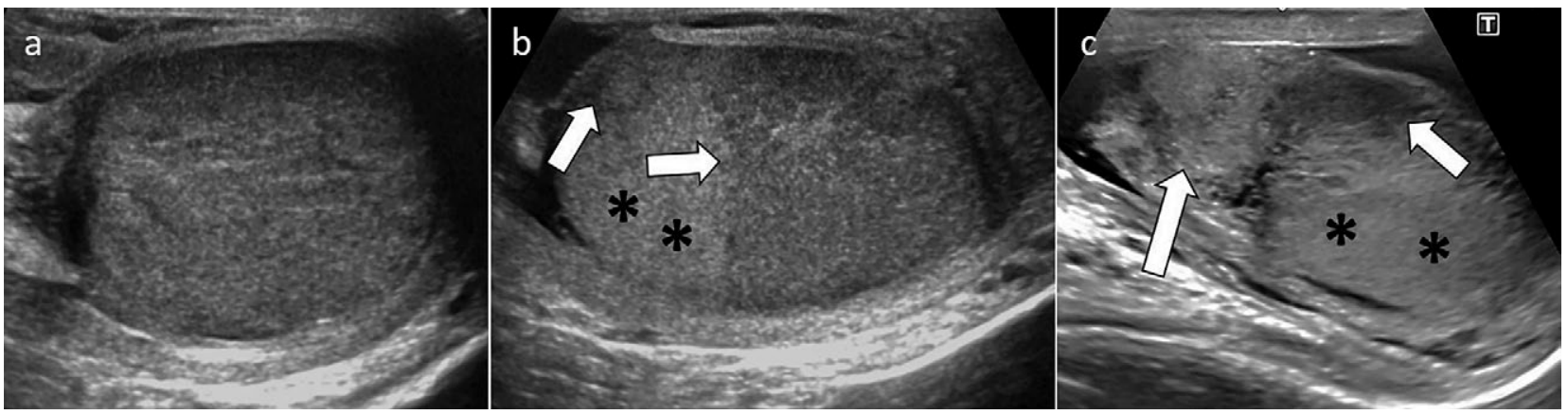

Fig 2. Three cases with BEO: a) diffuse enlarged testicle with heterogeneous parenchyma, diffuse involvement; b) two hypoechoic areas (arrows) and normal testicle parenchyma (asterisks) between two focal lesions, multifocal involvement; c) enlarged heterogeneous epididymis (long arrow) and focal hypoechoic area in testicle (short arrow). Normal testicular parenchyma (asterisks).

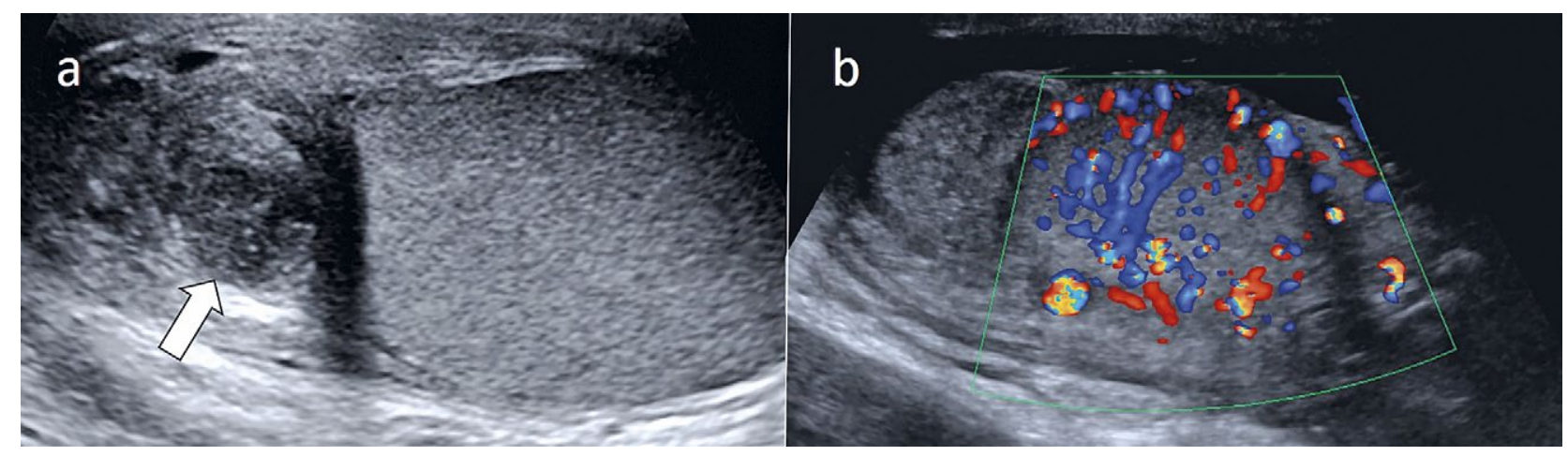

Fig 3. Enlarged heterogeneous epididymis (a). Vascularity of the testis (b).

Medical treatment was applied to all patients. In two cases with BEO, US-guided abscess drainage was also performed. Orchiectomy was performed in one case from each group due to unresponsiveness to the medical treatment.

\section{Discussions}

Early and accurate diagnosis of BEO is very important, otherwise BEO can cause morbidity and complications [6]. In a meta-analysis of 57 articles, it was observed that $10 \%$ of men with brucellosis had BEO [14] with variations between $2 \%$ and $20 \%[1,3,5,15,16]$. In our study $18.9 \%$ of men patients with brucellosis had BEO.

NBEO is more common than BEO, even in endemic areas for brucellosis. Chlamydia trachomatis and Neisseria gonorrhea are the most common causes of epididymoorchitis among sexually active males between 14 and 35 years [17]. For men, over 35 years of age, and prepubertal boys, the most common causes are Escherichia coli and Proteus mirabilis [18]. The serum agglutination test 


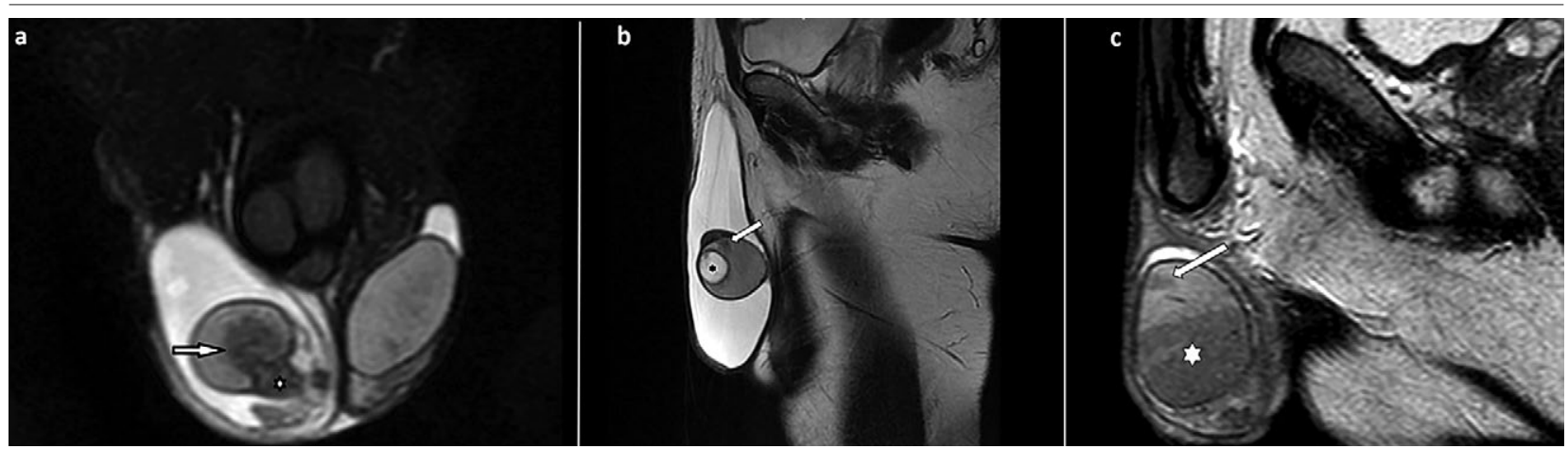

Fig 4. The coronal T2-weighted fat-suppressed image of a 13-year-old patient with BEO (a). The head of the epididymis (star) is swollen and hypointense. In the testicular parenchyma adjacent to the epididymis is a focal hypointense lesion (arrow) accompanied by a hydrocele. The sagittal T2-weighted fat-suppressed image of a 36-year-old patient with BEO (b), showing the presence of an abscess (star) and an adjacent hypointense focal lesion (arrow) accompanied by a hydrocele. The sagittal T2-weighted fat-suppressed image of a 24-year-old BEO patient (c), demonstrating the focal involvement of the right testis (star) and a second focal lesion (arrow).

is the most common adopted diagnostic tool for brucellosis. A titer ratio above 1:160 is considered a diagnostic criterion when accompanied by a coherent clinical presentation [19].

Most of the published studies regarding BEO are descriptive studies $[1,6,8,20]$ or related to the clinical and laboratory findings of BEO and NBEO [3,4,15,21-25]. Although US is considered as the first-applied imaging technique for the diagnosis of scrotal disease, to the best of our knowledge, there is only one study that compares US findings of BEO and NBEO [13].

Testicular inflammation develops in $20 \%$ to $40 \%$ of cases with the direct spread of epididymitis $[18,26]$. We detected involvement of both epididymis and testes in more than half of the cases in each BEO and NBEO groups (66.7\% and 53.7\%, respectively). However, isolated epididymis involvement was detected significantly more frequently in the NBEO group (35.1\%) compared with the BEO group (8.3\%). The faster spread from epididymis to testis parenchyma in BEO cases may be an explanation for this phenomenon. Another explanation may be the later appearance of brucellosis findings in BEO cases. In fact, Günlüsoy et al emphasized that the insidious onset and longer duration are two main characteristics of BEO which differs from NBEO [27]. Bilateral involvement has been reported in less than $10 \%$ of BEO cases in the current literature [1,8,13,15,21-23]. We found a higher rate of bilateral involvement in the BEO group $(n=5 ; 20.8 \%)$, significantly higher than in the NBEO group $(\mathrm{n}=13 ; 4.6 \%)$.

Papatsoris et al reported that abscesses developed in 8 of the 141 NBEO patients but was not present in any of the $17 \mathrm{BEO}$ patients [20]. Buzgan et al reported that 3 of 35 cases with BEO, developed an abscess, all requiring orchiectomy [23]. Unlike previous studies, we detected abscesses in 4 cases with BEO (16.7\%) and 5 cases $(1.8 \%)$ with NBEO and the frequency of abscess formation was found to be statistically significant higher in the BEO $(\mathrm{p}=0.003)$.

Unlike previous studies $[6,8,13]$, we evaluated cases with multiple lesions as multifocal lesions, where the rest of testicular parenchyma had a normal echotexture. Multifocal testicular involvement was observed in $14.3 \%$ of patients $(n=3 / 24)$ in the BEO group and in $5.9 \%$ patients $(n=11 / 285)$ in the NBEO group $(p<0.05)$. The identified multifocal areas can represent multiple abscess sites or areas of inflammation.

This study has certain limitations. The first concerns the retrospective design, which may have created bias due to the prior knowledge of diagnosis. Additionally, using US reports instead of US images may cause the use of unreliable data while evaluating US findings. Another limitation is the lack of an evaluation of the Doppler findings of the cases. Other limitations include the shortage of BEO cases, the presence of different and unidentified causative pathogens in NBEO cases and the absence of imaging findings of some cases during and after treatment. The time between disease onset and US examination was not considered, which could affect the US findings.

\section{Conclusion}

A careful US examination can prevent possible unnecessary orchiectomy, especially in regions with $\mathrm{Bru}$ cella endemicity. The possibility of BEO should be considered, especially when one or more findings, such as isolated testicular involvement, bilateral testicular involvement, abscess formation and multifocal testicular lesions, were detected during US examination.

\section{Conflict of interest: none}




\section{References}

1. Akıncı E, Bodur H, Çevik MA, et al. A complication of brucellosis: epididymoorchitis. Int J Infect Dis 2006;10:171177.

2. Venyo A. Brucellosis of testis and epididymis: a review of the literature. Br J Med Med Res 2015;10:1-19.

3. Colmenero JD, Reguera JM, Martos F, et al. Complications associated with Brucella melitensis infection: a study of 530 cases. Medicine 1996;75:195-211.

4. Colmenero JD, Munoz-Roca NL, Bermudez P, Plata A, Villalobos A, Reguera JM.. Clinical findings, diagnostic approach, and outcome of Brucella melitensis epididymoorchitis. Diagn Microbiol Infect Dis 2007;57:367-372.

5. Yurdakul T, Sert Ü, Acar A, Karalezli G, Akcetin Z. Epididymo-orchitis as a complication of brucellosis. Urol Int 1995;55:141-142.

6. Bayram MM, Kervancioğlu R. Scrotal grayscale and color Doppler sonographic findings in genitourinary Brucellosis. J Clin Ultrasound 1997;25:443-447.

7. Dogra VS, Gottlieb RH, Oka M, Rubens DJ. Sonography of the scrotum. Radiology 2003;227:18-36.

8. Patel PJ, Kolawole TM, Sharma N, Al-Faqih S. Sonographic findings in scrotal brucellosis. J Clin Ultrasound 1988;16:483-486.

9. Tanıdır Y, Gümrah A, Akbal C, Tarcan T. Brucella epididymo-orchitis as the first presenting sign of brucellosis: a case report and review of the literature. Marmara Med J 2008;21:56-60.

10. Domachevsky L, Peled N, Barzilai M. Sonography of Multifocal Brucella Orchitis. Ultraschall Med 2008;29(Suppl 5):275-276

11. Karam JA, Baker LA. Focal orchitis presenting as bilateral testicular masses. J Pediatr Urol 2007;3:337-339.

12. Cha WH, Choi YS, Kim SW, et al. Brucella Epididymorchitis: A Rare Cause of Testicular Mass. Korean J Urol 2007:48:359-362.

13. Ozturk A, Ozturk E, Zeyrek F, Onur K, Sirmatel O, Kat N. Comparison of brucella and non-specific epididymorchitis: gray scale and color Doppler ultrasonographic features. Eur J Radiol 2005;56:256-262.

14. Dean AS, Crump L, Greter H, Hattendorf J, Schelling E, Zinsstag J. Clinical manifestations of human brucellosis: a systematic review and meta-analysis. PLoS Negl Trop Dis 2012;6:e1929.
15. Memish ZA, Venkatesh S. Brucellar epididymo-orchitis in Saudi Arabia: a retrospective study of 26 cases and review of the literature. BJU Int 2001;88:72-76.

16. Turhan V, Acar A, Ates F, et al. Orchiectomy performed in two patients with brucella orchitis mimicking testicular tumour. West Indian Med J 2013;62:557-560.

17. Liu JM, Chang YH, Ho TW, et al. Patients with epididymoorchitis and meteorological impact in Taiwan: a nationwide population-based study. Can J Infect Dis Med Microbiol 2017;2017:1506857.

18. Dogra V, Bhatt S. Acute painful scrotum. Radiol Clin North Am 2004;42:349-363.

19. Pappas G, Akritidis N, Bosilkovski M, Tsianos E. Medical progress: brucellosis. N Engl J Med 2005;352:23252336.

20. Papatsoris AG, Mpadra FA, Karamouzis MV, Frangides CY. Endemic brucellar epididymo-orchitis: a 10-year experience. Int J Infect Dis 2002;6:309-313.

21. Celen MK, Ulug M, Ayaz C, Geyik MF, Hosoglu S. Brucellar epididymo-orchitis in southeastern part of Turkey: an 8 year experience. Braz J Infect Dis 2010;14:109115 .

22. Savasci U, Zor M, Karakas A, et al. Brucellar epididymoorchitis: a retrospective multicenter study of 28 cases and review of the literature. Travel Med Infect Dis 2014;12:667672.

23. Buzgan T, Karahocagil MK, Irmak H, et al. Clinical manifestations and complications in 1028 cases of brucellosis: a retrospective evaluation and review of the literature. Int $\mathrm{J}$ Infect Dis 2010;14:469-478.

24. Ibrahim AI, Awad R, Shetiy SD, Saad M, Bilal NE. Genito-urinary complications of brucellosis. Br J Urol 1988;61:294-298.

25. Navarro-Martïnez A, Solera J, Corredoira J, et al. Epididymoorchitis due to Brucella mellitensis: a retrospective study of 59 patients. Clin Infect Dis 2001;33:20172022.

26. Woodward PJ, Schwab CM, Sesterhenn IA. From the archives of the AFIP: extratesticular scrotal masses: radiologic-pathologic correlation. Radiographics 2003;23:215240.

27. Günlüsoy B, Vardar E, Arslan M, Çiçek S, Minareci S, Postaci H. Epididymo-orchitis and prostatitis due to brucellosis. Turk J Urol 2002;28:237-239. 